\title{
Esophageal Involvement by Hodgkin's Disease Mimicking Submucosal Tumor
}

Mediastinal Hodgkin's disease, while quite frequent, is usually asymptomatic, and chest radiographs only show a widening of the middle and upper mediastinum (1). We describe here the case of a patient with dysphagia as the initial symptom of Hodgkin's disease.

A 34-year-old man presented with progressive dysphagia and weight loss during the previous two months. Endoscopy (August 1991) diagnosed a bulging lesion of the mid-esophagus, considered to be a possible leiomyoma. Biopsies showed normal mucosa. Examination (Olympus EUM-3) showed a mediastinal hypoechoic tumor of $3 \mathrm{~cm}$ in thickness, with a coarse pattern, a possible calcification, and ill-defined boundaries (Figure 1). The tumor had developed in the esophageal wall itself, with enlarged regional lymph nodes. The diagnosis was a malignant esophageal tumor, probably a leiomyosarcoma. Computed tomography identified an $11-\mathrm{cm}-$ long formation in the posterior mediastinum that was in close contact with the aorta and compressing the trachea. Histopathology of a supraclavicular lymph node that was surgically removed showed Hodgkin's disease, of the nodular sclerosis type. The patient was treated by chemotherapy. A further endoscopic ultrasound examination (December 1991) showed a dramatic regression of the esophageal mass and lymph nodes (Figure 2). The patient underwent complementary mantle radiotherapy (40 Gy). Four years after the presentation, this patient was doing well, with no evidence of recurrence.

Lymphoma is a rare cause of dysphagia. In most cases, dysphagia occurs at the end stage of the disease, and is explained by external compression of the esophagus by affected mediastinal lymph nodes. Involvement of the esophageal wall itself is more unusual. Primary involvement, defined as lymphoma devcloping in the esophageal wall itself, is particularly rare (2); to date, only eight cases of isolated primary esophageal involvement by lymphoma have been 


\section{UCTN}

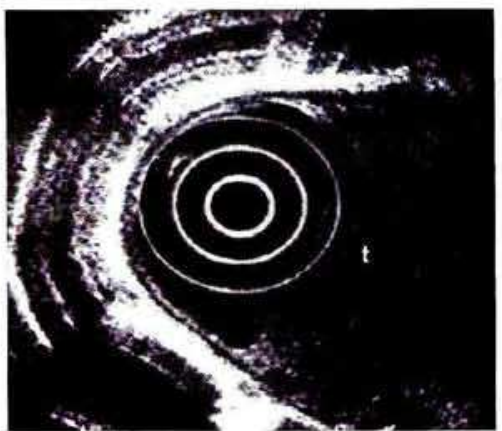

Figure 1: Hypoechoic mediastinal tumor ( $\mathrm{t})$. $3 \mathrm{~cm}$ thick, arising from the esophageal wall, with possible calcification and ill-defined boundaries.

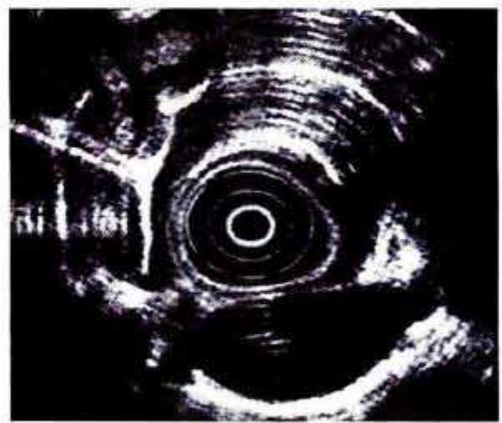

Figure 2: After chemotherapy at the level of the tumor, only a slight thickening in the left esophageal wall is visible.

published in detail: six in Hodgkin's disease (2) and two in non-Hodgkin's lymphoma $(2,3)$. In Hodgkin's disease, the nodular sclerosing subtype is predominant.

This case confirmed the usefulness of endoscopic ultrasound in the evaluation and staging of esophageal submucosal tumors and in the follow-up of patients with lymphoma treated with chemotherapy (4). It clearly shows that a specific diagnosis has to be obtained by pathology, because of the nonspecific endosonographic appearance of malignant submucosal tumors.

R. Bobichon, J. L. Gaudin, F. Romand, F. Pontette, J. L. Thaunat, J. C. Souquet Hepatology and Gastroenterology Service, Hôpital de la Croix-Rousse,

Lyon, France

\section{Unusual Cases and Technical Notes \$39}

\section{References}

1. Hellman S, Jaffe E, De Vita V. Hodgkin's disease. In: De Vita VT Jr, Hellman S, Rosenberg SA, editors. Cancer: principles and practice of oncology, $3^{\text {rut }}$ edn. Philadelphia: Lippincott, 1989: 1696-740.

2. Taal BG, Van Heerde P, Somers R Isolated primary esophageal involvement by lymphoma, a rare cause of dysphagia: two case histories and a review of other published data. Gut 1993; 34: 994-8.

3. Berman MD, Falchuk KR, Trey C, Gramm HF. Primary histocytic lymphoma of the esophagus. Dig Dis Sci $1979 ; 24: 883-6$.
4. Palazzo L, Roseau G, Ruskone-Fourmestreaux A, et al. Endoscopic ultrasonography in the local staging of primary gastric lymphoma. Endoscopy 1993; 25: 502-8.

Corresponding Author

R. Bobichon, M.D

Service d'Hépato-Gastroentérologie

Hôpital de la Croix-Rousse

93, Grande Rue de la Croix-Rousse

69317 Lyon

France

Fax: +33-4-72071613 